\title{
Keep on moving
}

Citation for published version (APA):

van Rhijn, L. (2009). Keep on moving. Maastricht University. https://doi.org/10.26481/spe.20090612lr

Document status and date:

Published: 12/06/2009

DOI:

10.26481/spe.20090612lr

Document Version:

Publisher's PDF, also known as Version of record

\section{Please check the document version of this publication:}

- A submitted manuscript is the version of the article upon submission and before peer-review. There can be important differences between the submitted version and the official published version of record.

People interested in the research are advised to contact the author for the final version of the publication, or visit the DOI to the publisher's website.

- The final author version and the galley proof are versions of the publication after peer review.

- The final published version features the final layout of the paper including the volume, issue and page numbers.

Link to publication

\footnotetext{
General rights rights.

- You may freely distribute the URL identifying the publication in the public portal. please follow below link for the End User Agreement:

www.umlib.nl/taverne-license

Take down policy

If you believe that this document breaches copyright please contact us at:

repository@maastrichtuniversity.nl

providing details and we will investigate your claim.
}

Copyright and moral rights for the publications made accessible in the public portal are retained by the authors and/or other copyright owners and it is a condition of accessing publications that users recognise and abide by the legal requirements associated with these

- Users may download and print one copy of any publication from the public portal for the purpose of private study or research.

- You may not further distribute the material or use it for any profit-making activity or commercial gain

If the publication is distributed under the terms of Article $25 \mathrm{fa}$ of the Dutch Copyright Act, indicated by the "Taverne" license above, 


\title{
Maastricht University
}

\section{Prof. dr. Lodewijk van Rhijn}

\author{
Faculty of Health, Medicine and Life Sciences
}

\section{Keep on Moving}

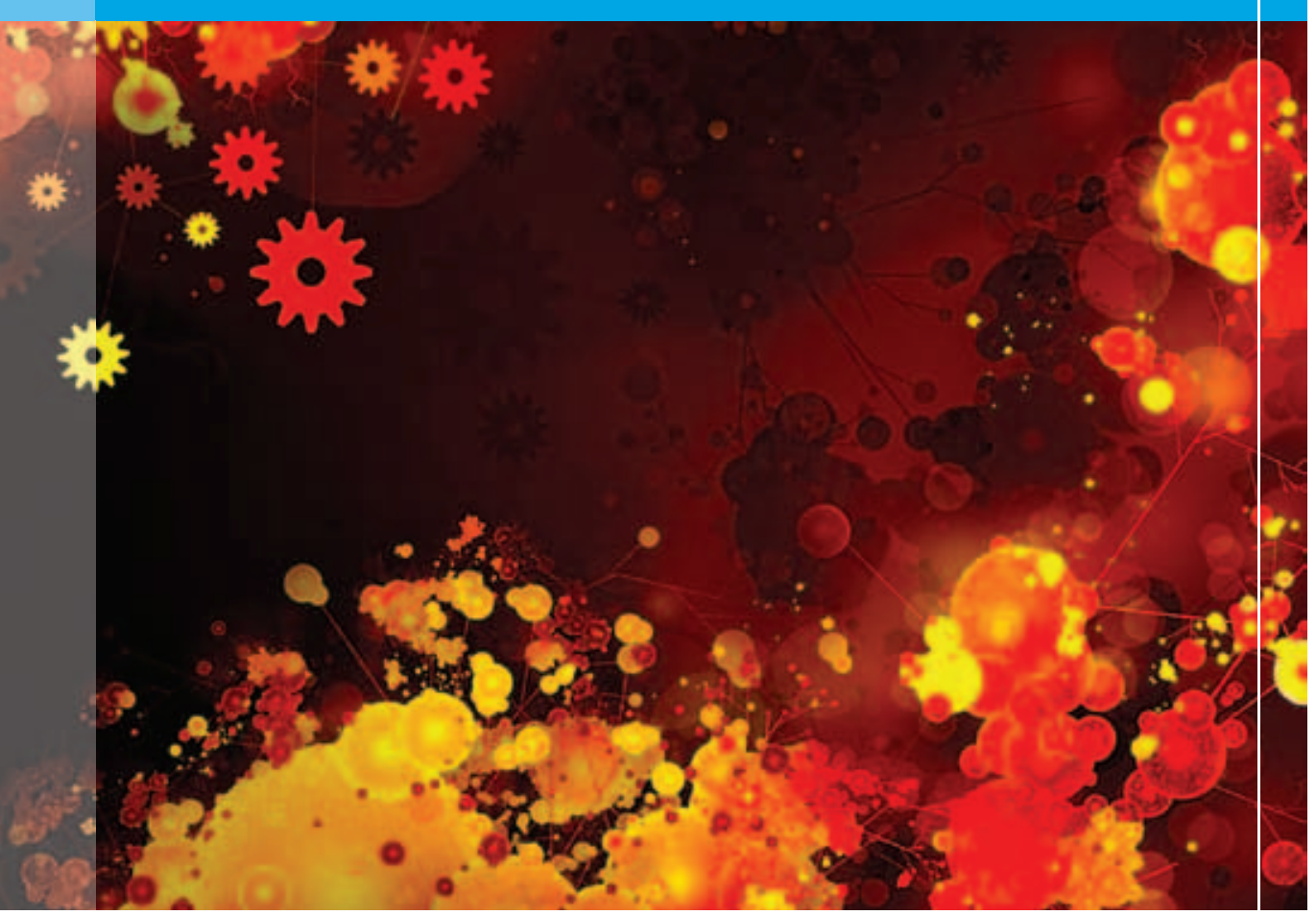


Keep on Moving 


\section{Colofon}

Ontwerp en druk: Océ Business Services, Maastricht

Omslag: M. Gelissen

ISBN: 9789056813178

NUR: 870

Alle rechten voorbehouden. Niets uit deze uitgave mag worden verveelvoudigd, opgeslagen in een geautomatiseerd gegevensbestand of openbaar gemaakt worden, zonder voorafgaande schriftelijke toestemming van de auteur of uitgever. 


\section{Keep on Moving}

In verkorte vorm uitgesproken bij de aanvaarding van het ambt van bijzonder hoogleraar Orthopedische Biotechnologie aan de Faculty of Health, Medicine and Life Sciences van de Universiteit Maastricht.

Op 12 juni 2009

Door Prof. dr. Lodewijk van Rhijn 


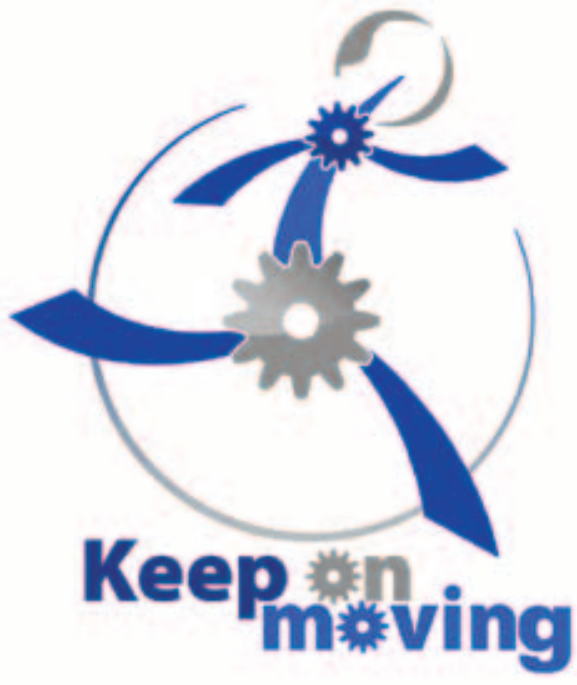


Mijnheer de Rector Magnificus, Geachte Decaan, Waarde collega's, Beste vrienden, Lieve familie, Dames en Heren,

Bewegen is voor elk mens van groot belang. Voor jong en oud.

Soms, en naar mate we ouder worden steeds vaker, zijn er beperkingen en ziektes waardoor bewegen niet meer vanzelfsprekend is. Voor de behandeling van bewegingsklachten hebben wij orthopeden de beschikking over tal van operatieve en niet-operatieve ingrepen. Door de technische ontwikkelingen van de laatste jaren is het mogelijk geworden de behandelingen nog meer dan we al deden te richten op het behouden of terugwinnen van kwaliteit van leven: We zoeken naar wegen om klachten en operaties te voorkómen, om te zorgen dat operaties minder belastend zijn, en om te zorgen dat patiënten jarenlang plezier hebben van een behandeling. Er is hierin al veel bereikt. Een knie- of heupprothese gaat gemiddeld 15-20 jaar mee. En denkt $u$ wat betreft minder belastende operaties aan bijvoorbeeld de kijkoperaties in gewrichten, waarbij de patiënt niet meer dagenlang is opgenomen maar nog dezelfde dag weer naar huis kan. We hebben veel successen geboekt maar de vragen van onze patiënten en onze eigen nieuwsgierigheid sporen ons aan verder te gaan, te blijven bewegen. We weten welke kant we op willen.

Om te kunnen bewegen is vanzelfsprekend ruimte nodig, maar ook vaste grond om op te staan. Alleen maar ruimte zonder ergens een punt om je voet op te zetten, maakt bewegingen doelloos. En we willen als mens, maar bijvoorbeeld ook als onderzoeksgroep of als afdeling, iets bereiken met onze bewegingen. De effecten van onze bewegingen kunnen worden versterkt of bijgestuurd door inspanningen van anderen die ondersteunen, aanvullen, ruimte maken of een voortrekkersrol vervullen. De vraag is nu: Hoe komen we tot een organisatie waarin voldoende ruimte is en waar voldoende vaste punten zijn om effectief en doelgericht te bewegen, met een groep mensen die elkaars bewegingen aanvullen en versterken, zodat 1 en 1 meer is dan 2? Hoe blijven we zodanig in beweging dat wij vernieuwend en effectief zijn? Hoe zorgen we ervoor dat we op plaatsen komen waar nog niet naar oplossingen gezocht is?

Ofwel: Hoe zorgen wij ervoor dat innovatie geen toeval is maar een logisch gevolg? 
Keep on Moving betekent voor mij: de patiënt die kan blijven bewegen. Maar ook artsen, onderzoekers en de organisatie die steeds in beweging blijven op zoek naar wat de patiënt en de maatschappij verder brengt.

In mijn rede wil ik deze aspecten van beweging, de letterlijke en de overdrachtelijke, belichten. Ik zal daarbij spreken over de vragen van de patiënt en over de mogelijkheden van innovatief onderzoek en ook zal ik spreken over de organisatiestructuur die nodig is om die beide bij elkaar te brengen.

Als eerste zal ik $u$ een overzicht geven van het werkveld van de orthopedische biotechnologie. Dit overzicht zal ik vervolgens illustreren met drie voorbeelden van wat biotechnologie kan betekenen voor de patiënt. De voorbeelden die ik heb gekozen zijn innovatieve behandeltechnieken, deels al toepasbaar, deels nog in ontwikkeling, die hier in het MUMC+ hun oorsprong hebben. Ik schets $u$ kort de ontwikkelingen van de afgelopen jaren en zal een idee geven van waar we in de toekomst naar toegaan.

Het tweede deel van mijn oratie gaat over de vraag: Hoe organiseren wij het vergaren van kennis? Kennis op het gebied van patiëntenzorg, onderwijs en wetenschap. En hoe leidt kennis tot innovatie? Wat zijn de voorwaarden voor innovatie en hoe zorgen we ervoor dat deze kennis uiteindelijk weer ten dienste komt van de patiënt?

\section{Orthopedische Biotechnologie, inleiding}

De klinische orthopedie houdt zich bezig met aandoeningen van het bewegingsapparaat. Aandoeningen van het bewegingsapparaat vormen één van de meest voorkomende oorzaken van beperkingen in het dagelijks leven. Ze zijn de belangrijkste lichamelijke reden voor arbeidsongeschiktheid en behoren tot de top-drie van klachten in de eerste lijn. Orthopedische klachten leiden zelden tot overlijden maar heel vaak tot chronische beperkingen en pijn.

Een belangrijk doel van orthopedische behandelingen is altijd geweest de kwaliteit van leven van de patiënt te verbeteren door het herstellen van de mobiliteit en/of het verminderen van pijn. Doel was en is het op een zo hoog mogelijk niveau behouden van het vermogen tot werk, sociaal leven en recreëren.

Door de vergrijzing van de Nederlandse bevolking zal het aantal patiënten met klachten van het bewegingsapparaat, in het bijzonder klachten door degeneratieve gewrichtsafwijkingen, de komende jaren 
stijgen. Daarnaast vormen sport en fitnesstraining in toenemende mate, ook op hogere leeftijd, onderdeel van een actieve levensstijl waardoor het bewegingsapparaat anders en meer wordt belast. Dit leidt tot een toename van acute en chronische overbelastingsletsels, en ook tot een toename van klachten als gevolg van degeneratieve processen. Actieve personen die sporten om hun gezondheid en welzijn te bevorderen willen zo min mogelijk het risico lopen deze gezondheidswinst verloren te zien gaan door ' bijwerkingen' van hun levensstijl. Dit soort tendensen maakt dat de vraag naar vroege, zo min mogelijk ingrijpende behandelingen van deze aandoeningen steeds dringender wordt. Twintig jaar geleden stelden we een totale heupoperatie bij een 55-jarige patiënt met ernstige artrose zo lang mogelijk uit. De patiënten van nu nemen geen genoegen meer met jarenlang verminderd functioneren op jonge leeftijd. Men leeft nu! Maar een prothese die bij een actieve 60-jarige wordt geïmplanteerd wordt veel zwaarder belast dan een prothese bij een 80-jarige. Er zijn dus andere protheses nodig. Niet alleen ouderen, ook jonge patiënten met chronische aandoeningen van het bewegingsapparaat vragen om andere en minder belastende behandelingen om de negatieve gevolgen van hun invaliderende ziektes zo veel mogelijk terug te dringen. Mijns inziens biedt de orthopedische biotechnologie fascinerende nieuwe mogelijkheden om aan deze terechte vragen tegemoet te komen.

Het werkveld van de orthopedische biotechnologie behelst het slaan van een brug tussen het klinisch vakgebied orthopedie en die ontwikkelingen binnen de biotechnologie die gericht zijn op ondersteuning, vervanging en/of herstel van weefsels van het steun- en bewegingsapparaat.

In de literatuur worden voor het begrip biotechnologie, verschillende definities gebruikt. Zo omschrijft de Raad voor Gezondheidsonderzoek in haar adviesrapport in 2006 het begrip als volgt: "Biotechnologie richt zich op het ontwikkelen van producten en processen met organismen of bestanddelen hiervan. Het gaat hier om de innovatieve technieken en processen waarmee vormen van biologisch leven kunnen worden geanalyseerd of die gebruikt kunnen worden voor de ontwikkeling van producten en productieprocessen".

Binnen de orthopedie wil ik de term biotechnologie breder definiëren zodat ook de ontwikkeling en toepassing van biomaterialen, zoals de heupprothese of een brace, hieronder vallen. Deze brede definitie van biotechnologie hanteer ik niet toevallig. Ik denk namelijk dat er verschillende manieren van kijken naar het menselijk lichaam nodig zijn om behandelingen te ontwikkelen die optimaal aansluiten bij wat nodig is om als mens te kunnen blijven bewegen. Hiermee bedoel ik dat 
het van belang is dat bijvoorbeeld technici met kennis van industriële materialen en onderzoekers met kennis van cellulaire processen samen met clinici aan problemen uit de kliniek werken. De verschillende visies op de 'werkelijkheid' dagen elkaar uit en roepen wederzijds vragen op. De gemeenschappelijke zoektocht naar bruikbare antwoorden leidt uiteindelijk tot een meer volledig begrip van de complexe processen die ons onderzoeksveld vormen. Een dergelijke manier van samenwerken geeft synergie en creëert een omgeving waarin echt innovatief denken mogelijk is.

Zoals ik al heb aangegeven kunnen we in het werkveld van de Orthopedische Biotechnologie drie gebieden onderscheiden.

Ik zal voor elk van deze drie deelgebieden aan de hand van lopende onderzoekstrajecten illustreren welke rol biotechnologische ontwikkelingen spelen in de verbetering.

\section{Biotechnologie en ondersteuning van het bewegingsapparaat.}

Hulpmiddelen om het bewegingsapparaat te ondersteunen worden van oudsher gebruikt in de orthopedie. Denk aan spalken, steunzolen en korsetten. In de afgelopen jaren is veel kennis vergaard over de biomechanische processen van het bewegingsapparaat. Door deze kennis te combineren met kennis over innovatieve industriële technieken en materialen hebben we nieuwe concepten ontwikkeld die leiden tot effectievere en minder belastende behandelingen. Een dergelijk traject vergt een lange adem. Dit wil ik illustreren aan de hand van de ontwikkelingen bij korsetbehandeling voor idiopatische scoliose.

Idiopatische scoliose is een drie dimensionale afwijking van de wervelkolom, bestaande uit zijdelingse verkrommingen gecombineerd met rotatie. De aandoening ontstaat bij het opgroeiende kind. De kans op progressie van de afwijking is het grootst als het kind snel groeit, zoals in de puberteit. Dit is dan ook meestal de leeftijd waarop de scoliose aan het licht komt. Idiopatisch betekent dat we de oorzaak van de aandoening niet kennen. De behandeling is vaak gecompliceerd en belastend. Indien in de wervelkolom een bocht is ontstaan van 20 tot 40 graden wordt deze meestal behandeld door middel van uitwendige correctie door een korset. Hiermee trachten we verdere toename van de bocht(en) te voorkomen. Indien de aandoening toch verder toeneemt, is vaak een operatie geïndiceerd omdat dergelijke forse vergroeiingen leiden tot afwijkingen aan hart en longen, tot pijn en tot duidelijk 
waarneembare afwijkingen in de stand van de rug (een zogenaamde bochel).

De gedachte achter korsetbehandeling is dat de wervelkolom door middel van uitwendige druk gedwongen kan worden een anatomisch juistere vorm aan te nemen waardoor de toename van de scoliose gestopt of afgeremd kan worden. In de 19e eeuw werden voor het eerst kinderen met scoliose ingegipst met dit doel voor ogen. Er werden ingenieuze apparaten ontwikkeld om de bocht zo goed mogelijk te corrigeren waarbij gebruik werd gemaakt van tractie en zijdelingse duwkrachten. Een van mijn voorouders, Hermanus Johannes van Rhijn, schreef in 1880 in Leiden zijn proefschrift over de methode Sayre waarbij men, ik citeer: De behandeling bestaat daarin: 'Dat men borst en buik met gipszwachtels inwikkelt, terwijl de patiënt aan hoofd en armen opgehangen is. Op deze wijze krijgt de lijder een korset aan, dat het gewicht van hoofd en romp en bovenste ledenmaten van de wervellichamen afneemt'. Het gips was niet afneembaar en werd om de paar weken vervangen.
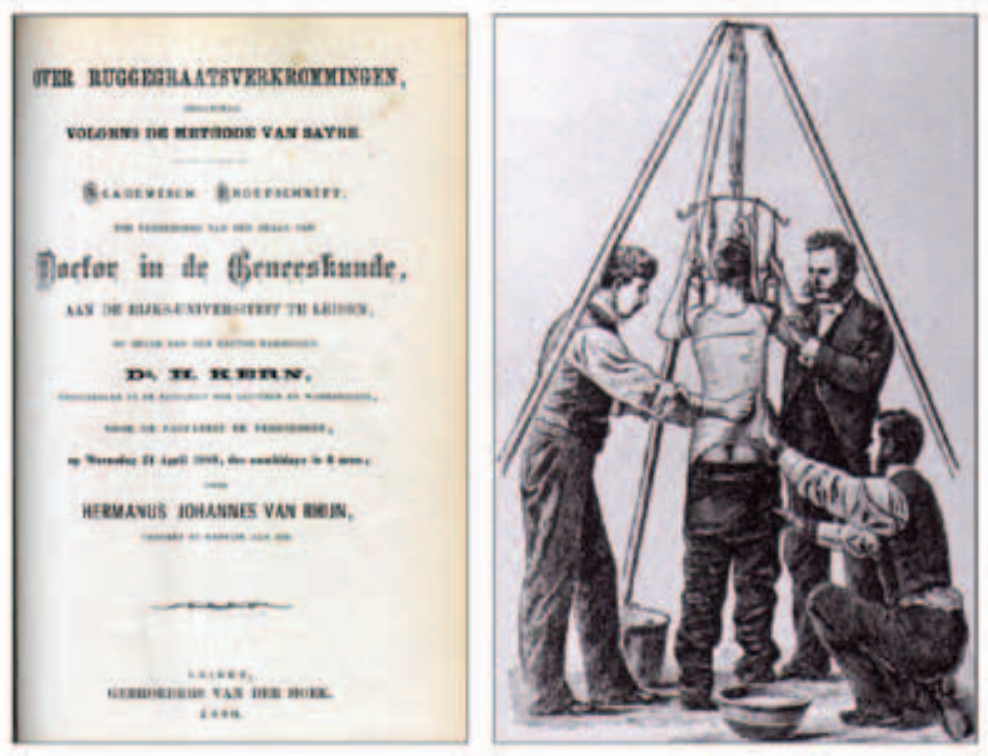
Toepassing van een afneembaar korset werd mogelijk met de komst van de Milwaukee brace in de jaren vijftig van de vorige eeuw. Dit korset was ontwikkeld om de wervelkolom van kinderen die een correctieve operatie hadden ondergaan te stabiliseren in de maanden na de ingreep. Deze operaties werden toen voor het eerst uitgevoerd. Ze waren risicovol en zeer belastend voor de patiënten, niet in het minst omdat na de operatie een langdurige periode van bedrust vereist was om de wervelkolom onbelast te laten genezen. In een poging bij andere patiënten progressie van de aandoening en daarmee operatie te voorkómen werd het korset aangepast voor dagelijks gebruik bij beginnende scoliose. Het dagelijks dragen van dit korset was erg onprettig omdat het zeer rigide was. Bovendien konden door de druk van de kinsteun groeistoornissen van de kaken optreden.

Omdat de vroege behandeling in voldoende mate effectief leek ter voorkoming van de belastende operaties werd dit korset verbeterd en uiteindelijk vervangen door verschillende braces zonder kinsteun. De Boston brace is hiervan het bekendste voorbeeld. Dit korset was wat minder oncomfortabel dan de korsetten met kinsteun maar nog steeds zeer rigide. Daarbij had het een achtersluiting waardoor de meeste kinderen het korset niet zelf aan konden doen.

$\cup$ kunt zich voorstellen dat het dragen van zo'n korset tegenwoordig bij pubers veel verzet oproept. De kans dat ze de behandeling volhouden neemt hiermee af. Dit leidt er de laatste jaren toe dat behandeling met een korset in een negatieve spiraal dreigt te geraken: Omdat de jongeren het onvoldoende dragen is het behandelresultaat niet bevredigend, hetgeen weer een reden is om het maar helemaal niet te dragen of voor te schrijven 'want het werkt toch niet'. Daarmee is onduidelijk geworden wat oorzaak is, en wat gevolg. Het blijft echter van groot belang de belastende operaties voor gevorderde scoliose zo veel mogelijk te voorkómen. En de enige behandeling waarvan op dit moment aannemelijk is gemaakt dat ze progressie van scoliose kan voorkómen is het dragen van een korset gedurende een groot gedeelte van de dag.

Alle redenen om een nieuw korset te ontwikkelen. We zijn op zoek gegaan naar manieren om, met behoud van de effectiviteit van het korset, het draagcomfort en daarmee de acceptatie door de patiënt te verbeteren. Hierbij dachten we aan ruimere bewegingsmogelijkheden, lichtere materialen, eenvoud in gebruik en, last but not least, een aantrekkelijke vormgeving.

We wilden uitkomen bij een behandeling waarvoor de mondige puber zelf mede verantwoordelijkheid kon dragen. Om te bespreken hoe we de 
verschillende gedachten verder in de praktijk konden uitwerken legden we onze ideeën voor aan de instrumentmaker. We begonnen ermee kleine aanpassingen te doen aan de Boston brace waardoor deze net iets gebruiksvriendelijker en comfortabeler werd.

In diezelfde tijd was ik bezig met mijn proefschrift "Dynamics in Idiopathic Scoliosis" Onderwerp van dit proefschrift was onder andere in detail vast te stellen hoe scoliotische bochten op bepaalde uitwendige krachten reageerden. We kregen meer oog voor de dynamische aspecten van de wervelkolomfunctie en -pathologie. We onderzochten vragen als: Hoe reageren wervelsegmenten op elkaar? In hoeverre beïnvloedt een correctie in bijvoorbeeld het lendetraject van de wervelkolom de stand van de borstwervels en vice versa? We verrichtten drukmetingen in het korset om het werkingsmechanisme van korsetbehandeling beter te kunnen doorgronden. De voorlopige uitkomsten van deze onderzoekingen gaven ons voldoende aanleiding om een nieuw korset te ontwerpen, waarbij we de nieuwe dynamische inzichten en de vraag naar een grotere gebruikersvriendelijkheid trachten te combineren. We maakten hierbij geen gebruik meer van gips, leer en metaal maar hadden toegang tot nieuwe, lichtere en flexibelere materialen.

We besloten ons ontwerp in te dienen voor de prijsvraag 'Van Idee tot BV' bij New Venture. Tot onze verrassing behoorden we tot één van de tien prijswinnaars tussen de meer dan 200 inzendingen. We kregen de mogelijkheid om het idee verder uit te werken en een businessplan te schrijven met als doel een BV op te richten. Echter vanuit universiteit en ziekenhuis kregen wij hiervoor geen ondersteuning zodat wij dit traject moesten afbreken. Blijkbaar was de tijd nog niet rijp voor intern ondernemersschap. Dit weerhield ons er niet van om door te gaan. Hoewel we bij de behandeling van patiënten konden vaststellen dat we sommige van onze doelen gerealiseerd hadden, kwamen we ook een aantal beperkingen tegen. Er bleven vragen over materiaalkeuze, werkingsmechanisme en vormgeving.

In 2006 ontvingen we gelden uit het subsidieprogramma Pieken in de Delta van het ministerie van Economische zaken. Dit programma heeft tot doel de ontwikkeling en uitwerking van innovatieve ideeën te stimuleren. Met deze subsidie werd een multidisciplinaire groep geformeerd bestaande uit technici, artsen en vormgevers afkomstig van TNO, Idee, WellDesign, Orthopedie 2000 en het azM. Vele contacten volgden, waarbij we eerst tijd hebben genomen om elkaars taal en achtergrond te begrijpen. Vervolgens volgden vruchtbare besprekingen die leidden tot concretisering van de ideeën. Een belangrijk innovatief 
onderdeel van het korset is de 'aantrekhulp': een biosensing-apparaat dat aangeeft of de corrigerende krachten in het korset optimaal zijn. De volgende stap zal zijn dat het systeem gaat anticiperen op bewegingen van de wervelkolom en de krachten automatisch gaat aanpassen. Tijdens de ontwikkeling is ook goed gekeken naar tends in de maatschappij om tot een eigentijdse vormgeving te komen. Het nieuwe korset ziet er nu als volgt uit (figuur) en lijkt aan alle eisen te voldoen die we van te voren hadden gesteld. We verwachten binnenkort de eerste resultaten van behandelingen te kunnen tonen. Er is belangstelling en er zijn contacten met het bedrijfsleven om dit korset op de markt te brengen.

\section{Nieuwe Brace}
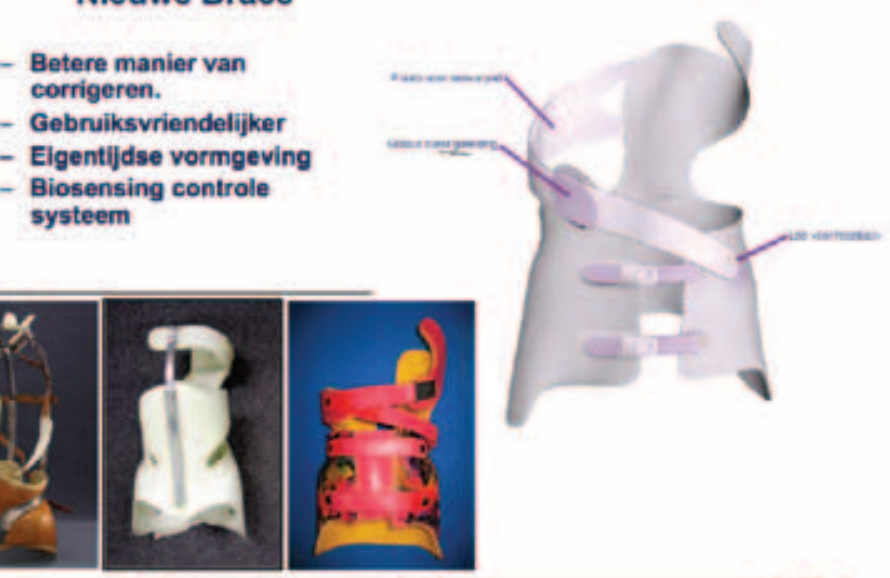

Aan de hand van dit voorbeeld heb ik $u$ willen tonen dat voor de totstandkoming van een nieuwe behandeling die werkt en patiëntvriendelijk is, het hebben van een goed idee alléén niet voldoende is. Effectieve innovatie zit in vele kleine verbeteringen die vanuit verschillende disciplines worden aangedragen en jarenlang stapje voor stapje worden uitgevoerd en geëvalueerd. Om deze reden is het belangrijk multidisciplinaire onderzoekslijnen op te zetten waarin het onderzoek op lange termijn gewaarborgd is en waarbinnen continue kruisbestuiving kan plaatsvinden. Zo creëren we de ruimte en de tijd om steeds terug te koppelen wat de verschillende betrokkenen ontwikkeld hebben en telkens te evalueren of dit is wat nodig is. Zo blijven we scherp houden welke verbeteringen verder mogelijk en gewenst zijn voor onze patiënten. 


\section{Biotechnologie en vervanging van delen van het bewegingsapparaat}

Dan kom ik nu toe aan een volgend gebied binnen de orthopedische biotechnologie: de implantatie-geneeskunde. Zoals ook de nietorthopeden onder u misschien weten, is het vakgebied orthopedie onder andere zo succesvol geworden door de ontwikkeling en toepassing van gewrichtsprothesen sinds de jaren zestig. De resultaten van gewrichtsvervangende operaties zijn goed en worden steeds beter: de totale heupprothese bijvoorbeeld is een van de meest effectieve en efficiënte behandelmethoden in de geneeskunde; kosteneffectief en met een zeer hoog patiënt-tevredenheidspercentage.

De implantatiegeneeskunde onderzoekt hoe een niet meer goed functionerend deel van het bewegingsapparaat kan worden vervangen door een implantaat. Hierbij maakt men gebruik van biomaterialen. Onder een biomateriaal wordt verstaan ieder materiaal (kunststof, keramiek, metaal, maar ook resorbeerbare substanties zoals scaffolds en biogels) dat in de geneeskunde wordt gebruikt in contact met het lichaam. De laatste jaren wordt hier en elders veel aandacht besteed aan de interacties van het biomateriaal met zijn omgeving. Was men aanvankelijk op zoek naar inerte materialen die geen schadelijke reacties in het lichaam veroorzaakten, nu richten we ons meer op (combinaties van) materialen die een zodanige reactie met de omringende weefsels aangaan, dat het implantaat een stimulans vormt voor genezing en door zijn eigenschappen bijdraagt aan een verlengde gebruikstijd.

Ik wil $u$ de mogelijkheden van de implantatiegeneeskunde schetsen aan de hand van ontwikkelingen rondom de tussenwervelschijf. Is het mogelijk om de 'succesformule' van bijvoorbeeld de totale heupprotheses te vertalen naar de behandeling van degeneratieve klachten van de wervelkolom?

In de jaren negentig zijn vanuit die veronderstelling tussenwervelschijfprotheses (totale discusprotheses) ontwikkeld om klachten als gevolg van degeneratie van de tussenwervelschijf te behandelen. Het succesvolle concept van de gewrichtsprothese, verwijderen van een kapot lichaamsonderdeel en vervangen door een prothese, werd min of meer één op één vertaald naar de 'gewrichten' van de wervelkolom in de hoop dezelfde goede resultaten te kunnen behalen. Die verwachting is helaas niet uitgekomen, zoals onder andere blijkt uit het onderzoek naar complicaties bij dergelijke protheses door Andre van Ooij in het azM. De tegenvallende resultaten zijn mijns inziens mede te verklaren doordat de 
biomechanica van de wervelkolom complexer en anders is dan men van te voren had gedacht. De manier van denken bij de ontwikkeling van de discusprotheses was achteraf gezien te weinig multi-dimensioneel.

Dit betekent niet, dat we niet verder moeten. We hebben juist veel geleerd: Door observatie van de complicaties en analyse van de resultaten weten we nu veel beter dan voorheen waaraan een discusimplantaat moet voldoen. Afgelopen jaren hebben wij samen met professor Koole van de afdeling Biomaterialen gewerkt aan de ontwikkeling van een partiële discusprothese: de nucleusprothese. Ik zal het concept waarop deze prothese gestoeld is, nader toelichten.

Degeneratie van een tussenwervelschijf is een chronisch proces dat verloopt in verschillende fasen. In de eerste fase treedt verval op van de driedimensionale structuur van de kern, de nucleus, van de tussenwervelschijf door afsterven van cellen en door veranderingen in de extracellulaire matrix. In een volgend stadium treden veranderingen op in de bindweefselband rond de nucleus (annulus fibrosus) waardoor deze minder stevig wordt. Door deze processen treden anatomische functionele verschuivingen op in dit wervelkolomsegment. Hierdoor worden ook de aanliggende wervels in het proces betrokken. Dit uit zich vooral in het harder worden van de dekplaten waardoor zich minder vloeistoffen met voedingsstoffen vanuit de wervel naar de tussenwervelschijf kan verplaatsen. De tussenwervelschijf, die geen eigen bloedvoorziening heeft, is van deze toestroom van voedingsstoffen afhankelijk. Als deze in- en uitstroom, die normaliter plaatsvindt onder invloed van de drukverschillen die er in verschillende houdingen in de wervelkolom optreden, stagneert, raakt het hele proces van degeneratie in een versnelling.

Op grond van deze bevindingen is het volgens ons van belang om zo vroeg mogelijk dit proces te keren, nog voor de weefsels en structuren rondom de nucleus zijn aangetast. Hier in het MUMC zijn we de laatste 4 a 5 jaar bezig met de ontwikkeling van een nucleusprothese met de bedoeling om in een vroege fase van degeneratie de nucleus te vervangen en zo de functie van de tussenwervelschijf te herstellen en het degeneratieproces te remmen, liefst te stabiliseren. Deze nucleusprothese wilden we op basis van nieuwe inzichten uit de fysiologie en vragen uit de kliniek, zo maken dat zijn fysisch-mechanische eigenschappen lijken op die van de echte nucleus. Dit hebben we vooral kunnen bereiken door gebruik te maken van een hydrogel, dwz een materiaal dat vloeistoffen kan opzuigen en afgeven afhankelijk van de mate van belasting van de tussenwervelschijf. Dit proces vindt ook plaats in de echte nucleus en is, 
zoals boven beschreven, essentieel voor de voeding en instandhouding van de hele tussenwervelschijf. Bovendien is deze eigenschap essentieel voor de biomechanische werking van de tussenwervelschijf in de wervelkolom. Daarbij is de nucleus radio-opaque, ofwel zichtbaar op röntgenbeelden. Dat heeft duidelijke voordelen bij toepassing en evaluatie in de kliniek.Tot op heden is er nog geen implantaat bekend dat deze eigenschappen heeft. De eerste testen lieten zien dat de nucleusprothese goed voldeed wat betreft de werking van de hydrogel: ook in het lichaam neemt het materiaal water op en scheidt het weer af onder invloed van drukverschillen. Bij deze testen kwam ook meteen een probleem aan het licht: Bij het plaatsen van de prothese is het nodig dat we de annulus fibrosus perforeren. Indien het hierdoor ontstane defect niet goed geneest, bestaat de kans dat de prothese gaat schuiven. Dat zou de resultaten van de operatie teniet doen. In de volgende ontwikkelingsfase moeten we de mogelijkheid van migratie van de prothese tot praktisch nul reduceren. Een oplossing voor het probleem van de migratie van de nucleusprothese zou kunnen zijn dat we het defect in de annulis fibrosus zodanig repareren dat verschuiven on mogelijk is. Hier liggen taken voor de orthopeed en de celbioloog. Een andere mogelijke oplossing is ervoor te zorgen dat de prothese zich op basis van zijn structuur of door toepassing van coatings, vasthecht aan zijn omgeving. Werk voor biochemici en celbiologen. Gezien het feit dat implanteren van een hydrogel nog niet vaak gedaan is, is ook nog relatief weinig bekend over hoe deze hydrogel zich onder langdurig belastende omstandigheden zal houden. Ook hiernaar zal verder onderzoek worden gedaan. Deze onderzoekingen en de verdere ontwikkeling van de nucleusprothese tot een implantaat dat geschikt is voor de behandeling bij patiënten is onderdeel geworden van één van de BioMedical Material subsidieprogramma's, waarbij bedrijven en kennisinstellingen samen naar biotechnologische oplossingen zoeken, nl het IDiDAS-project. 
Dan kom ik bij het ze voorbeeld: Hoewel de implantatie-chirurgie zeer succesvol is bij de behandeling van de gevolgen van artrose, denken we inmiddels niet alleen meer in termen van vervangen van kapot weefsel maar steeds meer in termen van vroege opsporing van degeneratie, voorkomen van verdere afbraak en herstel van weefsels. Hier komen we op het terrein van de regeneratieve geneeskunde.

\section{Herstel: Regeneratieve Geneeskunde}

Het lichaam heeft een natuurlijk vermogen om zich zelf te vernieuwen en te onderhouden. Dit biologische proces, waarbij de oorspronkelijke structuur en functie van weefsel wordt vervangen of hersteld middels vermeerdering van (stam)cellen, wordt weefselregeneratie genoemd. Het regeneratieve vermogen van het lichaam is beperkt. Het wetenschapsgebied regeneratieve geneeskunde gaat daarom na hoe weefselregeneratie kan worden nagebootst of gestimuleerd om beschadigde weefsels en organen te herstellen.

Ook voor regeneratieve geneeskunde worden verschillende definities gebruikt. De Koninklijke Nederlandse Akademie van Wetenschappen (KNAW) beschreef het begrip als volgt: "Regeneratieve Geneeskunde richt zich op functioneel herstel van beschadigd weefsel en organen door gebruik te maken van (de eigenschappen van) natuurlijk weefsel en cellen. De definitie omvat zowel het gebruik van cellen, het gebruik van cellen in combinatie met al dan niet afbreekbare biomaterialen, en het gebruik biomoleculen en/of biomaterialen alleen, die lokale regeneratie van weefsels en organen induceren".

Voor de orthopedie is vooral het onderzoek naar kraakbeenregeneratie, zoals dit ook al jaren op de afdeling orthopedie in het MUMC plaatsvindt, van belang. Artroseklachten ontstaan namelijk door beschadiging en verlies van de kraakbenige bekleding van gewrichtsoppervlakken. Verloren gegaan kraakbeen wordt niet spontaan hersteld. Dit ligt onder andere aan het feit dat kraakbeen een weefsel is met bijzondere eigenschappen. Het bevat geen bloedvaten maar wordt gevoed doordat gewrichtsvloeistof met voedingsstoffen onder invloed van drukverschillen in en uit het kraakbeen wordt verplaatst. De structuur van de extracellulaire matrix, bestaande uit collageen, proteoglycanen en water, stelt het weefsel in staat grote schuif- en drukkrachten te weerstaan. Kraakbeen blijkt een zeer ingenieus weefsel, veel moeilijker tot ontwikkeling te brengen of na te maken dan ooit gedacht.

Ik schets $\mathrm{u}$ kort de ontwikkelingen in het voorkomen van artrose door kraakbeenherstel gedurende de afgelopen jaren. In de jaren 
60 is men begonnen met een gecombineerde techniek namelijk het schoonmaken van kraakbeendefecten gevolgd door het opboren van onderliggend bot in de verwachting dat lokale stamcellen uit het bot zouden worden aangezet tot nieuwe kraakbeengroei. De resultaten waren wisselend en niet duurzaam. Het weefsel dat gevormd werd bleek wel tijdelijke pijnvermindering te geven maar bestond niet uit gewrichtskraakbeen. De volgende stap was om stamcellen of kraakbeenvoorlopercellen lokaal aan het defect aan te bieden b.v. door middel van kraakbeenvlies-transplantaties (perichondrium). De verwachting was dat de in het vlies aanwezige kraakbeen-voorlopercellen zich zouden vermenigvuldigen en kraakbeen zouden vormen. Er werd inderdaad kraakbeen gevormd in de defecten. Toch leidde deze ingreep niet tot bevredigende klinische resultaten, omdat het nieuwe kraakbeen bij te veel patiënten verkalkte. Vervolgens ging het onderzoek in de richting van autologe kraakbeentransplantaties: Kraakbeen werd bij de patiënt afgenomen, in het laboratorium opgekweekt en na een paar weken in het defecte gewricht teruggeplaatst. De resultaten lijken veelbelovend. Echter, deze techniek heeft als nadeel dat kraakbeencellen uit het lichaam moeten worden gehaald en in het laboratorium moeten worden opgekweekt. Dat is kostbaar, tijdsintensief en het geeft een verhoogde kans op infectie en verwisseling van preparaten.

Om deze nadelen zo goed mogelijk te ondervangen met behoud van de voordelen van het gebruik van lichaamseigen kraakbeen, hebben wij in het MUMC in een proefdiermodel de In Situ Incubator ontwikkeld. Het grote voordeel van deze werkwijze is dat kraakbeen in het lichaam zelf kan worden opgekweekt. De patiënt zal als het ware zijn eigen laboratorium zijn. De In Situ Incubator werkt als volgt. Om elk bot bevindt zich een botvlies, periost, waarin zich voorlopercellen voor bot en kraakbeen bevinden. Door beschadigingen, zoals bijvoorbeeld bij een fractuur, worden deze cellen geactiveerd, hetgeen uiteindelijk leidt tot botvorming zodat de beschadiging wordt gerepareerd. In dit herstelproces wordt eerst kraakbeen gevormd, dat later wordt omgezet in bot. De werking van de In Situ Incubator berust erop dat we een biogel inspuiten onder het periost. Het periost reageert op deze beschadiging met vermeerdering en ontwikkeling van voorlopercellen. Doordat de biogel geladen is met verschillende bioactieve stoffen zorgen wij ervoor dat de voorlopercellen zich wel ontwikkelen tot kraakbeencellen maar dat omzetting in bot wordt voorkomen. Het kraakbeen kunnen we vervolgens 'oogsten' en transplanteren naar een kraakbeendefect in een gewricht. 


\section{De ' In Situ Incubator'}

Doel: Kraakbeen kweken in het lichaam van de patiënt zelf!

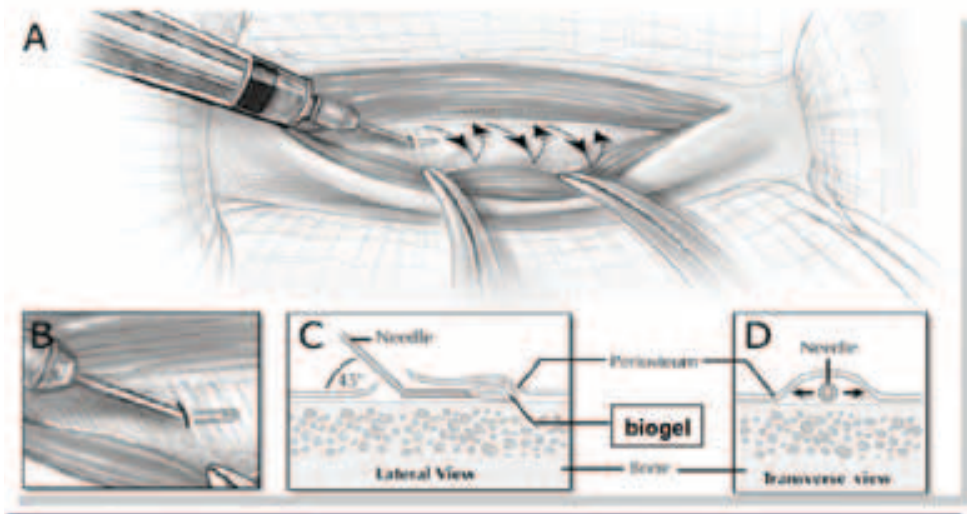

Prik onder botvlies

Achterlaten biogel ander het botvies

\section{De 'In Situ Incubator'}

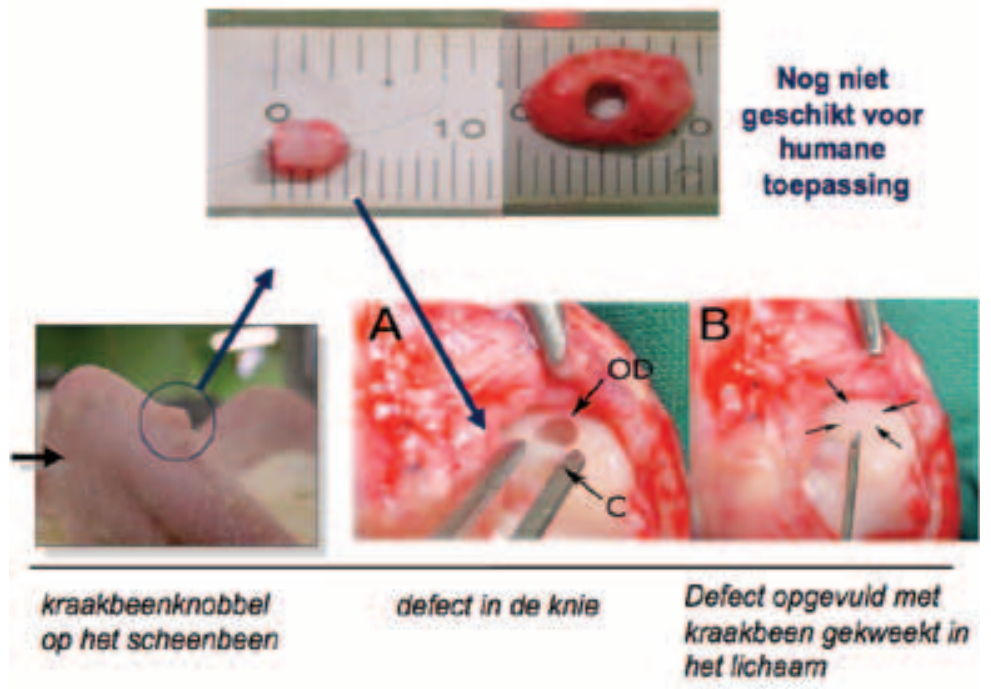


Met behulp van een grant van het Reumafonds wordt het volledige potentieelvan dezenieuwe benaderingvoorherstelvan kraakbeendefecten onderzocht. Ons eerste doel is om de vorming van kraakbeen in het lichaam te optimaliseren door variaties in de samenstelling van de biogel. In een studie bij kraakbeendefecten bij konijnen hebben we gezien dat bij ongeveer $70 \%$ van de beschadigde gewrichten die op deze manier werden behandeld kraakbeenherstel optrad. De resultaten bleken niet alleen afhankelijk van de aard van de verschillende toegevoegde bioactieve stoffen maar ook van de structuur van de biogel. Deze structuur bleek een belangrijke factor in het ontwikkelen van kraakbeen. Het achterliggende mechanisme hierbij ontging ons. Om de regeneratie van weefsel optimaal te kunnen beïnvloeden was het nodig meer te weten over de interactie van de cel met zijn micro-omgeving en de moluculaire processen die hierbij betrokken zijn, de zogenaamde 'pathways'.

We hebben diverse modelsystemen opgezet waarbij de differentiatie vanuit stam en/of voorlopercellen tot kraakbeen onderzocht wordt. De lopende projecten, om het In Situ Incubator-concept verder te exploreren richten zich op het bestuderen van:

- Omgevingsfactoren, zoals zuurstofgehalte en mechanische druk.

- Cellulaire factoren, zoals wat is de invloed van andere cellen zoals, fibroblasten.

- Moleculaire factoren, zoals diverse groeifactoren (TGF $\beta$, FGF2, IGF) en pharmaceuticals (indomethacine, dexamethasone, valproic acid).

Geleidelijk begrijpen we steeds meer van de complexiteit van dit systeem en kunnen we steeds beter gebruik maken van het feit dat de ontwikkeling van stamcel tot functioneel weefsel een combinatie is van intern gestuurde en extern gestuurde processen.

In het begin lag de focus van ons onderzoek op het ontrafelen van cellulaire systemen om, eventueel in combinatie met biomaterialen, via tissue engineering te komen tot implanteerbare weefsels. Later begrepen we dat we meer moesten weten van de micro-omgeving en moleculaire processen om de ontwikkeling van stamcel tot weefsel te kunnen beïnvloeden.

Dit bleek voor ons een circulair proces te zijn. Laboratoriumbevindingen testten we in weefselmodellen en dierstudies. De uitkomsten van deze studies, die natuurlijk anders waren dan verwacht, leidden weer tot nieuwe vragen. Proefopstellingen om deze vragen te beantwoorden gaven weer aanwijzingen voor nieuwe stoffen die in de biogel konden worden geïncorporeerd, en zo voort. 
De reden dat ik hier zo uitgebreid op inga, is gelegen in het feit dat dit onderzoeksproces een continue afstemming vergt tussen onderzoekers op fundamenteel niveau en onderzoekers op preklinisch en klinisch niveau.

Door deze manier van samenwerken hebben we de "In Situ Incubator" verder ontwikkeld en zijn we nu in de fase dat we dit concept kunnen gaan vertalen naar humane toepassingen.

Maar dit onderzoek brengt naast gegevens om onze biogel te optimaliseren ook andere feiten aan het licht, die van direct belang kunnen zijn in de kliniek. Dit belang wordt natuurlijk alleen maar opgemerkt op het moment dat er clinici in het laboratorium komen of basale onderzoekers in de kliniek.

Eén van onze ontdekkingen is dat bepaalde pijnstillers, NSAID's, de overgang van kraakbeen naar bot remmen. Dit was in het laboratorium van belang bij de kweek van bruikbaar kraakbeen. Maar in de kliniek zou het zo kunnen zijn dat deze pijnstillers ook de genezing van een botfractuur remmen. In dat geval een ongewenste bijwerking. Deze gegevens nodigen uit om samen met de collega's van de afdeling traumatologie nader te worden geanalyseerd en geëvalueerd ten aanzien van hun klinisch belang.

Als tweede voorbeeld van onverwachte spin-off wil ik noemen dat we verschillende relaties hebben gevonden tussen ontstekingsreacties en kraakbeengroei. Algemeen is bekend dat ontsteking leidt tot afbraak van kraakbeen zoals bij reumatoïde artritis. Uit ons onderzoek kwam als onverwachte bevinding naar voren dat ontsteking ook een positieve stimulans kan hebben op kraakbeengroei. Ook deze gegevens zouden we natuurlijk graag nader onderzoeken op hun klinische toepasbaarheid. Hierbij zouden we dan een brug slaan tussen de klinische vakgebieden reumatologie en orthopedie. Het oude adagium dat de reumatologen patiënten behandelen bij wie gewrichtsklachten te maken hebben met ontstekingsprocessen en de orthopeden patiënten met slijtage of artrose, lijkt op fundamenteel vlak onhoudbaar.

Voer voor samenwerking. 


\section{Organisatie en structuur}

In mijn inleiding heb ik aangegeven dat deze rede, 'Keep on Moving', uit twee delen zal bestaan. In het eerste gedeelte heb ik aan de hand van 3 voorbeelden aangegeven hoe we, uitgaande van de behoeftes van patiënten en van klinische observaties, bezig zijn biotechnologische kennis te vergaren en te implementeren. $\mathrm{Nu}$, in het tweede gedeelte, zal ik uiteenzetten op welke manier we ervoor kunnen zorgen dat onderzoek leidt tot effectieve en gewenste oplossingen. Kennis alleen is geen garantie voor innovatie. Voor innovatie, voor succes, is meer nodig. Als eerste is het belangrijk om te definiëren wat het doel is van het onderzoek binnen onze afdeling. Wat willen we bereiken en wanneer vinden we het onderzoek succesvol? Om resultaten te boeken, moet daarover voldoende eensgezindheid bestaan bij de verschillende belanghebbenden. In een universitair medisch centrum moet mijns inziens het doel van onderzoek zijn: het ontwikkelen van behandelingen die leiden tot verbetering van de kwaliteit van leven van patiënten. Waarom is dit niet meer vanzelfsprekend? Waarom moet hierop heden ten dage bewust worden gestuurd? Enkele decennia geleden voerden bij onderzoek de observaties aan het bed (en op de poli) de boventoon en werd het laboratoriumonderzoek op een kamertje op de afdeling door de clinicus verricht, naast diens patiëntenzorg. Met het ingewikkelder worden van het onderzoek kwamen de laboratoria buiten de kliniek. Zo ontstonden er twee werelden. Beide werelden hebben zich in de loop van de jaren sterk ontwikkeld en zowel de behandeltechnieken als het onderzoek zijn veel complexer en specialistischer geworden. Men doet onderzoek er niet meer 'even bij'. In een artikel in Mediator, het tijdschrift van ZonMW, verwoordt Prof. Pinedo helder de gevolgen van deze situatie: 'Het naast elkaar staan van die twee werelden belemmert de ontwikkeling in de geneeskunde. Het gevaar is dat de kliniek vervalt in het uitproberen van nieuwe therapieën en het waarnemen van de complicaties hiervan. Maar de bijdrage van de clinici aan de ontwikkelingen kan veel groter en effectiever zijn. Klinische observaties moeten weer richting geven aan het laboratorium onderzoek'.

Om dit te verwezenlijken, met als doel te komen tot effectieve innovatieve behandelingen, hebben we binnen onze groep een eigentijdse strategie ontwikkeld. Ik noem dit de translationele onderzoekspiraal.

De laatste jaren is veel geschreven over translationeel onderzoek als de vertaalslag van laboratorium naar kliniek, als onderzoek gericht op het vinden van klinische toepassingen voor fundamentele kennis. Mediator heeft er een hele Special aan gewijd. Hierin kwam naar 
voren dat Nederland sterk is in fundamenteel medisch-biologisch onderzoek. Ook het klinisch onderzoek staat op hoog niveau. Dankzij de vorming van Universitair Medische Centra in de laatste decennia, is er een nu infrastructuur voor samenwerking tussen fundamentele en klinische onderzoekers. Maar met het samenvoegen van twee groepen, basale onderzoekers en clinici, heb je niet zomaar een vertaling van laboratoriumvindingen naar toepassingen in de kliniek. In de dagelijkse praktijk merk je dat deze groepen een andere taal spreken en, misschien belangrijker nog, een ander cultuur hebben. Deze cultuurverschillen hebben onder andere te maken met de wijze waarop het onderzoek in de verschillende groepen wordt aangestuurd en met wat in de verschillende groepen wordt gezien als 'succesvol onderzoek'. Voor de ene groep is het doel een hoge impact factor, voor de ander telt meer de maatschappelijke relevantie van hun onderzoek. Beide attitudes zijn legitiem en het is van belang elkaars inbreng en importantie te waarderen. Als hierover geen duidelijkheid is, krijgen we de situatie dat iedereen vanuit zijn eigen domein gaat aangeven waarom zijn of haar werk belangrijk is. Polarisatie en strategisch gedrag zijn het gevolg.

In 2007 heeft de Raad voor Gezondheidsonderzoek (RGO) een advies geschreven over translationeel onderzoek in Nederland. Ik citeer: 'De RGO beschouwt translationeel onderzoek als een fase in de kennisketen. Het omvat alle stappen vanaf de identificatie (in patiënten of patiëntenmateriaal) van aangrijpingspunten voor diagnostiek, preventie of therapie tot en met vroeg-klinische toepassingen in de praktijk. Vraagstellingen kunnen zowel uit de klinische praktijk als het laboratorium afkomstig zijn'.

Ik zie translationeel onderzoek op onze afdeling niet zozeer als een fase in de kennisketen, maar veel meer als een continue proces waarbij fundamentele en klinische onderzoekers geïntegreerd bezig zijn hun kennis te vergroten en in te zetten om te komen tot innovatieve behandelmogelijkheden. Ik zou dit willen visualiseren als een spiraal, een helix, waarin het onderzoek als het ware al cirkelend door de verschillende onderzoeksafdelingen uiteindelijk uitmondt in een klinische toepassing. Dit proces noem ik de translationele onderzoeksspiraal.

Zoals gezegd zijn klinische observaties en vragen van de patiënten startpunt en richtinggever voor de onderzoekspiraal. De clinicus stuit op een niet goed te behandelen situatie en zoekt binnen het team van (pre-)clinici en fundamentele onderzoekers naar kennis en kunde, naar aanknopingspunten om een begin te maken met de oplossing 


\section{Translationele OnderzoeksSpiraal}

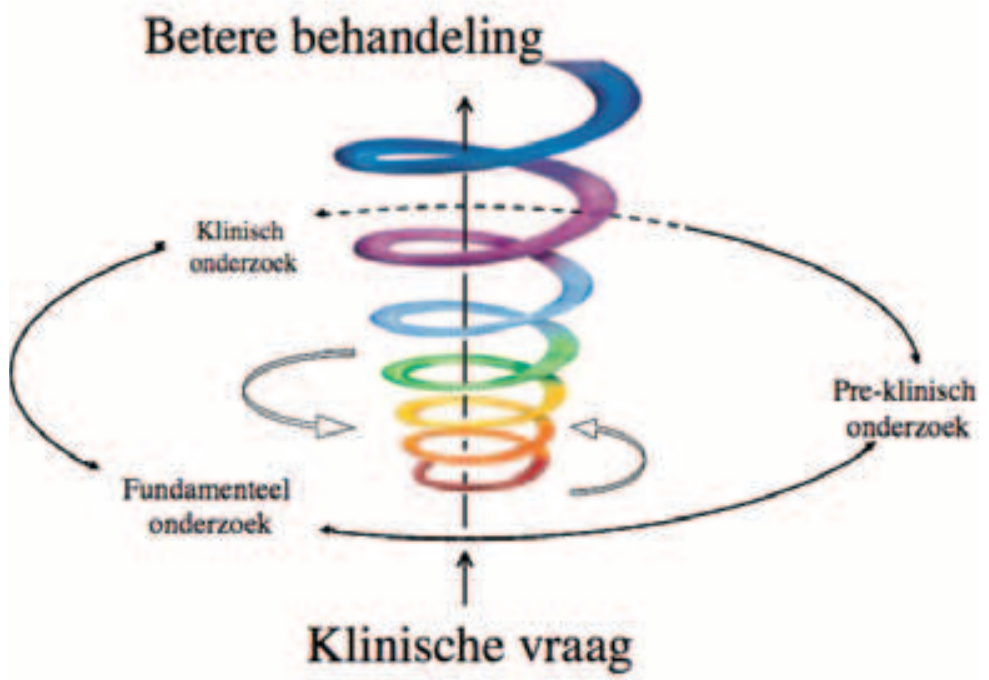

van het probleem. Vanaf hier wordt de spiraal in beweging gezet, men gaat op verschillende manieren en op verschillende niveaus op zoek naar methodes die kunnen leiden tot oplossingen. Steeds worden de gevonden deeloplossingen teruggekoppeld naar elkaar en vergeleken met het gewenste resultaat op de verschillende niveaus. Gedurende het onderzoek doemen ook nieuwe vragen op die weer met het doorlopen van de spiraal langs de verschillende basale onderzoekers en clinici moeten worden opgelost. De ervaring is dat de deze cirkelbeweging vele malen, steeds op een ander niveau, gemaakt moet worden voordat de onderzoeksspiraal vernieuwende klinische toepassingen oplevert. Men heeft een lange adem nodig, en tijd om in elkaar te investeren.

Al doende merkt men echter dat men veel inspiratie bij elkaar kan opdoen. Ook worden er verrassende nieuwe vindingen gedaan die weer kunnen leiden tot nieuwe onderzoeksspiralen.

Om de translationele onderzoeksspiraal te laten draaien en samen tot het einddoel te komen, is het van belang dat we als een team functioneren. Alle teamleden werken aan hetzelfde doel en zijn even belangrijk. Het onderzoek beweegt zich voort doordat de onderzoeksbal rond wordt gespeeld richting het doel. Elk persoon weet dat hij de bal 
kan terugverwachten en hij kan hierop anticiperen. Zo gaat het spel steeds vloeiender lopen. In plaats van in feedback- systemen te denken, werken we met feed-forward-systemen: Anticiperen op wat gaat komen, doen voordat het opgedragen is, omdat men het gemeenschappelijke doel belangrijk vindt, meedenkt en plezier heeft in het vinden van oplossingen. Je vraagt van de teamleden dat zij, naast intelligentie, ook creativiteit, leergierigheid, volhardendheid en interne motivatie bezitten om samen tot oplossingen te komen. Hoe beter de verschillende onderzoekers en clinici op elkaar zijn ingespeeld, hoe beter het team functioneert en hoe groter de kans op innovatieve vindingen.

Teamwerk houdt ook in dat er binnen het team betrokkenheid en verantwoordelijkheid voor elkaar en voor het gemeenschappelijke doel bestaat. Het team dat mij voor ogen staat is namelijk zelf verantwoordelijk voor de inhoud van het werk en voor de procedures die nodig zijn om het werk goed te doen en te komen tot resultaten.

Als we deze multidisciplinaire translationele strategie willen laten functioneren, moet de beoordeling van de onderzoeksuitkomsten en de onderzoekers ook geënt zijn op dit systeem. In de praktijk betekent dit een beoordeling op persoonlijk- en op team-niveau. Bijvoorbeeld, de fundamentele wetenschapper wordt meer beoordeeld op de impact factor van zijn artikelen en de clinicus op de mogelijke klinische toepassing van de vindingen. Bovendien worden alle deelnemers beoordeeld op samenwerking en op de gemeenschappelijke output.

Een ander belangrijke voorwaarde om de onderzoeksspiralen te laten draaien is dat we de infrastructuur rondom een aantal thema's daadwerkelijk neerzetten. Daarmee creëren we voldoende kritische massa om continuïteit op de lange termijn te waarborgen en maken we duidelijk in welke onderdelen wij excelleren.

Deze infrastructuur hebben we in het MUMC+ voor artrosebehandeling en wervelkolompathologie reeds ontwikkeld.

Ten eerste de artrosebehandeling:

- De zorg voor patiënten met artrose is sinds 2005 gestructureerd in de Artrose Kliniek Maastricht (AKM). In deze Kliniek is door stroomlijning en efficiency een herkenbare en aantrekkelijke zorglijn gecreëerd voor patiënten en ziekenhuisorganisatie. In de AKM wordt multidisciplinair onderzoek verricht volgens het principe van de translationele onderzoeksspiraal op bijvoorbeeld de gebieden van prothesiologie en vroegbehandeling van artrose. 
Als tweede de behandeling van wervelkolompathologie:

- De afgelopen jaren hebben er grote veranderingen plaatsgevonden in de behandeling van aandoeningen van de wervelkolom. Wereldwijd wordt er veel geïnvesteerd in kennis en technische mogelijkheden om deze aandoeningen optimaal te behandelen. Nieuwe ontdekkingen op het gebied van botheling, implantaten en niet op de laatste plaats minimaal invasieve operatietechnieken volgen elkaar in snel tempo op. In het Maastricht UMC is er een nauwe samenwerking met de afdeling neurochirurgie op het gebied van patiëntenzorg en onderzoek. Momenteel wordt er intensief gewerkt aan het oprichten van een Spine Centrum waarin de afdelingen neurochirurgie, pijnbestrijding /anesthesie en orthopedie samen de zorg voor de patiënt en het bijbehorende onderzoek ter hand nemen.

Voor beide onderzoekslijnen geldt dat er translationeel onderzoek wordt verricht op basaal, preklinisch, klinisch en top-referent niveau. De onderzoekslijnen zijn ook onderling weer met elkaar verbonden, hetgeen inhoudt dat er op elk niveau van onderzoek een directe samenwerking is. De twee lijnen zijn complementair en synergetisch.

Bij de beantwoording van de vraag hoe we er voor kunnen zorgen dat onderzoek leidt tot effectieve en innovatieve oplossingen voor de patiënt, is het belangrijk ons te realiseren wat het belangrijkste goed is van een universitair medisch centrum. Naar mijn mening is dat kennis. Kennis op het gebied van onderwijs, wetenschap en patiëntenzorg. Het zijn de mensen in de organisatie die deze kennis bezitten en de kwaliteit van de interactie tussen deze mensen om kennis te delen, bepaalt de mate van innovatie binnen een organisatie.

Een universitair medisch centrum heeft de positie en de kennis om onderzoek te initiëren en te sturen. We moeten die positie ook innemen. Het idee dat nieuwe behandelingen alleen kunnen worden ontwikkeld met steun van de industrie klopt niet. Tenslotte zijn het de artsen en onderzoekers die dicht bij de patiënten staan. Zij horen en zien wat nodig is. Laten we daar gebruik van maken.

Een UMC heeft alle ing rediënten, van kliniek tot fundamenteel onderzoek, om zelf nieuwe behandelingen te initiëren. Ik zie de afdeling waar ik werkzaam ben dan ook als een centrum voor orthopedische innovatie. 
Voordat ik nu aan het einde van mijn rede toekom, wil ik graag nog de volgende beelden met $u$ delen.

Orthopedie is een vakgebied in beweging, midden in een veranderende maatschappij. De samenleving reageert op de ontwikkelingen in de orthopedie en blijkt daar haar eigen vorm aan te geven. Bijvoorbeeld in de mode.

De volgende dia's kreeg ik opgestuurd van de vooraanstaande trendanaliste Christine Boland. Ik kan het daarom niet nalaten u even mee te nemen naar de modevoorspellingen voor 2010. Zij noemt deze trend: Bionic Beauty.

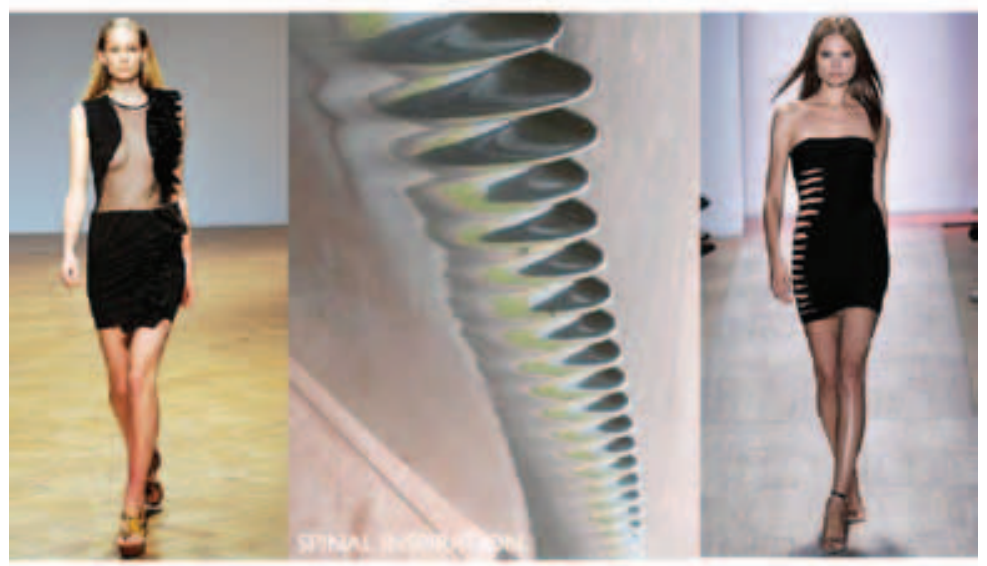

summer 2010

BIONIC BEAUTY

Orthopedie blijkt verrassend invloedrijk.

\section{Dankwoord}

En dan ben ik nu aan het einde van mijn rede gekomen en wil ik vele mensen bedanken. Als afdeling orthopedie hebben wij een aantal jaren geleden een bepaalde beweging ingezet. Na roerige tijden, waarin we aanvankelijk het basale onderzoek kwijtraakten, laten we deze week zien dat we er sterker zijn uitgekomen. Door de inzet en het enthousiasme van velen staat het onderzoek weer; getuige de publicaties, de geldstroom, en natuurlijk deze week, met het symposium, de lezingen-serie en de website.

Dit hoogleraarschap zie ik als de bekroning voor al die inzet. 
Op deze dia vermeld ik een aantal van de vele personen binnen het MUMC die hieraan hebben meegewerkt. Ik wil iedereen, en met name mijn collega-orthopeden en onderzoekers, bedanken voor het vertrouwen en de ruimte die zij mij gaven.

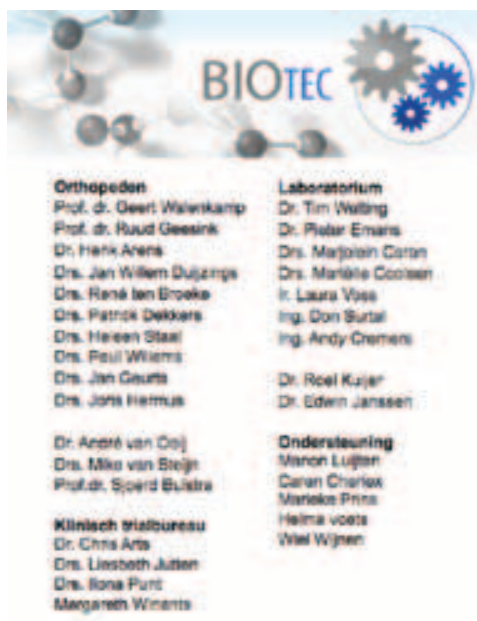

MAASTRICHF

Voleculaire Cenetica

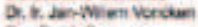
Dr. I rank Scanen

\section{Biemateriaien}

Prot. of La Koole

D. Kuse Saralexe

D. Mesno Kressch.

Dh flese wan Hisoy Conbank

Medieal Fieid Lab

D. Nos Culbemans

Din. darine Bomara

2. Ftome Ras

D. dody tharies:

Dre Luc Wratane
Anna

Fonds

caphri
Afd. Nourochirugie

De icers ver serithne

Aft Epidemiologe

Pret it Rob de Bir

Ons Plew Laften

Aamaren Wrens

Dit alles kan niet zonder de onvoorwaardelijke steun van mijn vrouw Mieke en mijn kinderen, Fay en Gijs, die dachten dat het na het voltooien van mijn proefschrift wel wat rustiger zou worden! Het blijft continue een zoektocht naar de balans tussen mijn enthousiasme voor het vak en mijn liefde voor mijn gezin.

Rest mij nog te zeggen: Mensen blijf in beweging, Keep on Moving.

Ik heb gezegd. 


\section{Referenties}

Boele JH (2007) Novel Radiopaque biomaterials for spinal surgery [Thesis]. Maastricht, The Netherlands: Universiteit Maastricht.

Emans PJ (2007) Towards in situ chondrogenesis of periosteum. A novel approach for cartilage repair [Thesis]. Maastricht, The Netherlands: Universiteit Maastricht.

Koninklijke Nederlandse Akademie van Wetenschappen. Kansen voor de regeneratieve geneeskunde in Nederland. Amsterdam: Koninklijke Nederlandse Akademie van Wetenschappen, concept rapport 2009.

Raad voor Gezondheidsonderzoek. Advies onderzoeksagenda medische biotechnologie. Den Haag: Raad voor Gezondheidsonderzoek, 2006; Publicatie nummer 53.

Raad voor Gezondheidsonderzoek. Translationeel onderzoek in Nederland - Van Kennis naar kliniek. Den Haag: Raad voor Gezondheidsonderzoek, 2007; Publicatie nummer 55 .

Van Rhijn LW (2005) Dynamics and relationships in Idiopathic scoliosis [Thesis]. Maastricht, The Netherlands: Universiteit Maastricht.

ZonMw. Translationeel onderzoek in Nederland. Mediator 2007; nr 6.

ZonMw. Adulte stamcellen op weg naar de kliniek. Mediator 2008; nr 7. 
